Cuadernos de Filología Clásica. Estudios Latinos

ISSN: 1131-9062

https://dx.doi.org/10.5209/cfcl.77307

\title{
Latín y romance: la transmisión culta y popular de los nombres del Zeus faber Linnaeus
}

\author{
Ana Moure Casas ${ }^{1}$
}

Recibido: 20 de abril de 2021 / Aceptado: 20 de junio de 2021

Resumen. Se trata en este trabajo de la transmisión culta y, de otra parte, popular de los distintos nombres del animal identificado por los naturalistas como Zeus faber L., así como de sus motivaciones desde el latín al romance hispano, donde se dibuja muy diferenciada dicha doble transmisión. De una parte, se registran términos transmitidos por filólogos, traductores y eruditos, algunos de ellos bien conocidos, que dejaron su huella en la creación de cultismos hispanos, como 'ceo' y 'fabro' aun hoy vigentes, pero de escasa vitalidad. De otra, se hallan términos habituales en la lengua actual, aparentemente sin raíces clásicas, metafóricos y (re)motivados por textos y leyendas cristianas, como 'gallo' y 'sampedro'.

Palabras clave: Léxico; ictiónimos cultos y populares; latín vulgar; romance; transmisión; motivación.

\section{[en] Latin and Romance: the cultured and popular transmission of Zeus faber}

\section{L. names}

\begin{abstract}
This work deals with the cultured and popular transmission of the different names of the animal identified by naturalists as Zeus faber $L$. as well as his motivations from Latin to Hispanic romance, where this double transmission is drawn very differently. On the one hand, terms transmitted by philologists, translators and scholars are recorded, some of them well known, which left their mark on the creation of Hispanic cultisms, such as 'ceo' and 'fabro' still in force today, but with little vitality. On the other, there are common terms in the current language, apparently without classical roots, metaphorical and (re) motivated by Christian texts and legends, such as 'gallo' and 'sampedro'.
\end{abstract}

Keywords: Lexicon; cultured and popular ichthyological terms; Vulgar Latin; Romance; transmission; motivation.

Sumario. I. Introducción. II. La transmisión culta de los nombres latinos. 1. El ictiónimo zaeus. 2. El ictiónimo faber. III. Los nombres populares hispanos. 1. El ictiónimo 'gallo' 2. El ictiónimo '(sam) pedro'. IV. Textos y leyendas cristianas en la remotivación. V. Recapitulación final. Bibliografía.

Cómo citar: Moure Casas, A. «Latín y romance: la transmisión culta y popular de los nombres del Zeus faber Linnaeus», Cuad. Filol. Clás. Estud. Lat. 41.1 (2021), 37-55.

\section{Introducción}

El objetivo de este trabajo es ofrecer un ejemplo de transmisión culta y popular observando la historia de los sucesivos nombres de la especie piscícola identificada por los naturalistas como Zeus faber L. desde el latín al romance hispano, subrayando las

1 Universidad Complutense de Madrid. Correo electrónico: amicis@ucm.es. 
motivaciones de dichos nombres y su perceptibilidad por los hablantes en distintas circunstancias culturales.

Las fuentes documentales más empleadas como punto de partida, aparte de algunos textos griegos, han sido las Haliéuticas, Columela y Plinio, junto con trabajos de lexicografía generales y específicos del mundo antiguo y posterior, citados en la bibliografía. De estos estudios, en especial del debido a Saint-Denis (1947), proceden los presupuestos de partida de la mayor parte de los trabajos posteriores, incluido este. Así, el reconocimiento de que, como ya habían señalado los antiguos (Varrón, LL.5.77), la semejanza con los animales terrestres es el primer elemento motivador del nombre, sobre todo detalles de su forma externa, su color, olor, sabor, sus sonidos, alguna propiedad o rasgo de carácter y su hábitat o procedencia geográfica ${ }^{2}$. Prosiguió en España este trabajo señero, sin modificar los puntos de partida, pero hasta incluir el s. VII, Baltar (1975) y, ya dentro de la ictionimia romance hispana, las importantes investigaciones de Manuel Alvar (1970 y ss.) y posteriormente de Arias-De la Torre (2019) se sumaron a las aportaciones de Giammarco (1963-64) y especialmente de Cortelazzo (1965), en cuyo estudio se incluían todos los nombres mediterráneos actuales y se describía el universo metafórico desplegado alrededor de este animal particular que constituye la especie más representativa de los Zeidos. Por nuestra parte, en una perspectiva diacrónica, hemos añadido a los datos sobre la distribución actual de acuerdo con la Geografía lingüística, el examen de textos técnicos medievales recogidos en glosarios y, detenidamente, los textos de humanistas que fueron herederos de los autores clásicos de obra científica y a la vez precursores de la ictiología moderna, como Conrad Gessner y sus fuentes tanto anteriores -Paolo Giòvio, Pierre Gilles- como coetáneas -Guillaume Rondelet, Ippolito Salviani, Pierre Belon-, autores de obras prestigiosas y útiles por su base en la ciencia antigua y su nueva forma de tratar los temas, incluyendo las identificaciones precisas de las especies mediante descripciones amplias y dibujos, de los que se hace mención ya en la portada de las ediciones. Algunas de ellas fueron libros de lectura de los humanistas españoles que se ocuparon desde una perspectiva científica y filológica del tema que nos ocupa en este trabajo, esto es, la recepción en España de los ictiónimos trasmitidos por los autores latinos clásicos y también la llegada de nuevos términos, metafóricos - como 'gallo’ y sus compuestos-y religiosos - remotivados por la figura de san Pedro- que desplazaron a los nombres anteriores del Zeus faber L. ${ }^{3}$.

En el mundo latino fue conocida esta especie piscícola por los dos nombres de zaeus y faber, que constituyen nuestro punto de partida. Y, aunque es habitual que

2 Saint-Denis (1947, XXII-XXV) señalaba el carácter motivado por metáfora de la mayor parte de los nombres de los peces y la dirección en la que había actuado la motivación, de lo más a lo menos conocido, así como su incidencia en las siete características enunciadas, que permitían agrupar los 260 ictiónimos latinos registrados por él en siete grupos. Cifras similares fueron aceptadas por Battisti (1960-1,63-67) a propósito de la recepción en el mundo latino de la terminología griega referida exclusivamente a nombres de peces. Se acepta comúnmente las dificultades de dar cifras exactas - errores de transmisión en una terminología tomada del griego, deficiente atestiguación, descripciones escasas e imprecisas de las características morfológicas. Además, otros problemas, como el uso de diminutivos que pueden designar un animal diferente (Baltar 1975, 2, 320), y los de la homonimia y polisemia, escasamente documentada en latín.

3 Las obras de estos naturalistas, de la primera y segunda generación, seleccionados por haber sido fuentes reconocidas de Gessner y, sobre todo, por su huella en autores españoles, son hoy accesibles online. Las ediciones utilizadas se citan con detalle en la bibliografía final. De la familia de nombres relacionados con la figura de san Martín en España se ha tratado en otro lugar (Moure 2020). Otras designaciones de la especie no constituyen el objetivo de este trabajo, por lo que sólo se mencionan tangencialmente. 
en el ámbito piscícola de las lenguas vivas actuales se den con frecuencia casos de sinonimia $-\mathrm{y}$, en ocasiones, de homonimia-, en cambio, por las características del vocabulario ictiológico latino, no es frecuente que las fuentes hayan transmitido más de un nombre de la misma especie. En efecto, la terminología ictiológica latina clásica, en cuya transmisión tuvieron un papel importante grandes eruditos, como Varrón, Columela y, sobre todo, Plinio el Viejo, resulta ser en su inmensa mayoría de origen griego y ha sido transmitida así, a menudo en forma de simples transcripciones, probablemente de forma intencionada por un objetivo práctico. Quiere esto decir que, aparte de otras razones, como el hecho de que las fuentes fuesen generalmente griegas y las obras latinas que las recogían fuesen de erudición con escaso margen de atención a la lengua oral, debió de intervenir también una razón de utilidad práctica, similar a la que llevó siglos después a biólogos y naturalistas a utilizar el latín para crear una terminología científica capaz de ofrecer la identificación precisa de las especies por encima de las variantes locales y temporales de sus nombres. Por ello, es un hecho destacable que, en el caso de esta especie piscícola, nos hayan llegado las dos denominaciones, la transcripción griega y un nombre latino que acaso pueda considerarse calco de otro, también griego, de modo que cabe examinar las posibles diferencias de perceptibilidad y uso de dos términos, en principio, coetáneos y sinónimos.

\section{La transmisión culta de los nombres latinos}

\section{El ictiónimo zaeus}

Una mirada a los contextos latinos que tratan de esta especie piscícola nos lleva a un texto de Columela (8.16.9) en el que ofrece la información de que en su tierra natal de Gades el faber, del Atlántico, era considerado uno de los pescados de mejor clase, al que se daba, a la antigua usanza, el nombre de zaeus. El pasaje se halla en un contexto sobre la construcción de viveros para la cría de peces de mar. Columela se expresa en términos similares a los empleados en sus capítulos sobre la ganadería de la villa y, en consecuencia, recomienda la estabulización de los peces, criando las especies propias de cada lugar. Las dos denominaciones del pez no constituyen el foco de la narración, sólo se subrayan al hilo del relato.

Non enim omni mari potest omnis esse, ut helops, qui Pamphilio profundo nec alio pascitur, ut Atlantico faber, qui generosissimis piscibus adnumeratur in nostro Gadium municipio -eumque prisca consuetudine zaeum appellamus- $-{ }^{4}$

El aparato crítico confirma las dos formas editadas, tanto faber, sin ninguna discrepancia, como zaeum, cuya grafía se apoya en la forma ofrecida por los dos manuscritos más antiguos de Columela, sumada al consenso de algunos recentiores ${ }^{5}$.

4 «Desde luego no puede estar cualquier especie en cualquier mar, como el 'hélope', que se cría en el profundo mar de Panfilia y no en otro, y como en el Atlántico el 'fabro', que se cuenta en nuestro municipio de Gades entre los pescados de más categoría -y lo llamamos ‘ceo' a la antigua usanza-»).

5 El aparato crítico de la edición de Josephson (1955, en Lundström et al.) muestra que la grafía zaeum se basa en las lecturas de los códices S y A, de época carolingia y en el consenso de los principales recentiores, representado por R: z(a)eum SAR zacum a raeum i. El editor considera estos manuscritos (en especial S, el más antiguo) los de mayor autoridad en lo ortográfico (plerique uiri docti nostrae aetatis, recte mea sententia, putant etiam 
Aunque Plinio no suele seguir a Columela, recoge la información de este y, consecuentemente, los dos nombres faber y zaeus. Esta última forma -en realidad, una adecuada enmienda del editor Sillig a la lectura zeus de los códices medievales plinianos, incluidos los más antiguos-, es hoy la grafía adoptada por las ediciones más autorizadas en el pasaje correspondiente a PLIN.9.686.

Est et haec natura, ut alii alibi pisces principatum optineant, coracinus in Aegypto, zaeus, idem faber appellatus, Gadibus, circa Ebusum salpa, obscenus alibi et qui nusquam percoqui possit nisi ferula uerberatus; in Aquitania salmo fluuiatilis marinis omnibus praefertur ${ }^{7}$.

Plinio da otro sentido a la noticia de Columela, aprovechándola para un objetivo más propio de su enciclopedia. Al igual que en la mayor parte de los temas, ofrece un apartado dedicado a cuál era en su época el orden de valoración económica o social del producto del que está hablando. A Plinio le interesa siempre establecer un ránking, sobre todo cuando con ello puede sorprender al lector mostrándole una curiosidad o provocándole una extrañeza que le exija reflexionar; en este caso, una curiosa valoración de los pescados. Plinio subraya como hecho excepcional el que en Cádiz el zaeus, que precisamente también se llamaba faber 'obrero', se considerase de primera categoría, lo mismo que en las cercanías de Ibiza se valorase al máximo el pez llamado salpa, considerado en otras partes obscenus, e incluso que en otros lugares llegase a preferirse un pescado de río a los de mar. Todo este pasaje se halla contextualmente dentro de una amplia paradoja moralizante que se cierra con la conclusión de que mientras en Roma se pagaban cantidades astronómicas por un buen salmonete, en otros sitios eran peces despreciables en Roma los que se valoraban.

En suma, los datos proporcionados por los dos autores nos permiten saber que faber era el nombre latino popular al uso que había desplazado a la transcripción del griego zaeus, ya entonces considerada antigua, aunque en Cádiz era ésta la que se empleaba. Podemos sospechar que podía deberse en alguna medida al conservadurismo que se atribuye a las zonas alejadas de la metrópoli, pero también a que el significado de faber presagiaba un producto de mala calidad, y no era el caso de un pescado, allí del Atlántico, muy cotizado.

in rebus orthographicis codices ueteres et bonos auctoritatem quandam habere-ib.p. X-), aunque no siempre consignó si todos ellos utilizaron invariablemente la grafía ae, propia de época carolingia -para diptongos e hiatos-. No obstante, todas las aquí aducidas apoyan de distinta manera la grafía -ae-. De otro lado, el resto de las lecturas (reum g etum o et cum cjoe et eum dquü tharum 1) indica que la transmisión tampoco muestra una relación formal con el teónimo Zeus.

6 Curiosamente Sillig (1852, vol. II ad l.) ofrece la forma zeus en Plin.9.68. En cambio, la edita con la grafía ae en PLIN.32.148 fabri sive zaei, reivindicándola además como enmienda propia (zaeus nos) en el Index criticus librorum XXXII-XXXVII (nuevas vacilaciones aparecen en las recopilaciones generales de todos los índices, publicadas póstumamente en 1858). En todo caso, colaboraron a favor de su acierto el que, en este último pasaje, el empleo del término en plural dificultaba su admisión como teónimo y, de otra parte, las lecturas de los manuscritos, como zaes VRd, zais B -el ms. mejor y más antiguo, s. X., considerado fundamental para este libro-zaeus $\mathrm{S}$, avalaban, en medio de sus divergencias, la forma-ae-. Mayhoff y editores posteriores aceptaron su enmienda unificando la grafía - ae-y extendiéndola a ambos pasajes plinianos, aunque sin señalar el aval que ofrecía el precedente de Columela.

7 «Existen además unas características naturales de tal índole que algunos pescados, según en dónde, se consideran de primera categoría: el 'coracino' en Egipto, el 'ceo', también llamado ‘fabro', en Cádiz; cerca de Ibiza, el pez salpa, que en otras partes da asco y que nunca puede cocer bien si no se varea con una caña; en Aquitania se prefiere el salmón de río a cualquier pescado de mar». 
En otras palabras, el examen de los pasajes de ambos autores nos lleva a creer que faber era percibido como un término popular y despectivo, por las fuentes y por lo que sabemos de la escasa consideración social de los oficios, lo cual es congruente con la pésima calidad del producto al que hacía referencia en Roma ${ }^{8}$.

$\mathrm{Y}$, con respecto al término zaeus, no se ofrece ningún indicio de alguna relación con el nombre del dios en las fuentes citadas, con independencia de lo que este nombre haya podido sugerir posteriormente a los filólogos sobre sus raíces indoeuropeas originarias y su significado problemático. Como ya se advierte por la lectura ofrecida en las ediciones actuales de ambos autores clásicos, la grafía zae-, restituida razonablemente, lo distanciaba del teónimo. Del mismo modo, su etimología más acep-

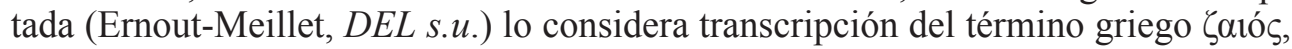
recogido, acaso por su carácter de rareza, por el lexicógrafo Hesiquio de Alejandría,

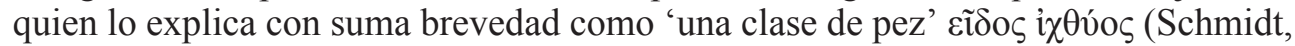
vol. II 252). Esta etimología fue también conocida y aceptada por Gessner (1558, 440), anticipándose a los editores de Plinio. De acuerdo con ello, zaeus pertenece al grupo de los préstamos directos del griego al latín, como la mayor parte de los ictiónimos.

Sin embargo, la lectio uulgata de los códices medievales ofrecía la forma zeus, con esta grafía que se plasmó en comentarios al texto (así, en las famosas Castigationes, en las que Ermolao Bárbaro, ad NH IX 68 anotó: scribo fabri sive zeus), en ediciones antiguas y en las traducciones de Plinio, que constituyeron una vía primordial de acceso a su texto. Ya en una de las primeras, debida a Landino ([1476]1543, 215), la grafía Zeo fabbro expresa la asociación total con el nombre propio del dios. De las españolas, todavía en la debida a Hernández se halla la forma latina de los códices zeus. Fue Jerónimo de Huerta quien empleó la transcripción correcta - del término latino y este, a su vez, del griego- ceo alejándose del nombre del dios y dando lugar a un nuevo cultismo9. Este término pasando por varios diccionarios del s. XVIII, donde se definía como el nombre de un pescado en Cádiz, llegó hasta la actualidad, aun con las dudas, tan razonables, de si debía ser considerada palabra realmente castellana por parte de Corominas-Pascual, s.u.

A su vez, en otros textos la grafía común zeus provocaba la relación inmediata con el nombre del dios e inspiró incluso la denominación científica del pez por parte de los naturalistas, que lo identificaron como Zeus faber L., en la idea de conmemorar la nomenclatura antigua.

\section{El ictiónimo faber}

El llamado en latín faber sin duda es inconfundible por su aspecto singular, que hoy lo lleva estar en la mayor parte de los acuarios. Entre los rasgos morfológicos de

\footnotetext{
8 Plinio es el primero en señalar la paradoja de que en la Bética fuese tan valorado un pescado que para los romanos no era estimable. Tampoco lo era, en general, para los humanistas: Pierre Gilles, p. 557, anotó la peculiaridad de los españoles de apreciar desde antiguo tal pescado. Después, Pierre Belon, p.150, afirmaba que en Roma no se valoraba-Romae paruo erat in pretio- hasta la llegada de los cardenales franceses a la muerte del Papa Paulo III, y Gessner, pp.39-440, recoge la anécdota.

9 La fecha que consta en su edición del libro nono de Plinio es 1603, así como el año anterior en las dedicatorias a Felipe III y al Duque de Lerma, si bien Huerta advierte que la traducción de este libro estaba ya concluida antes de la de los libros VII y VIII, publicados en distintas fechas; entre ellas, en 1599 por el editor L. Sánchez en Madrid.
} 
interés para nuestro tema por haber sido impulsores de la motivación de algunos de sus nombres en distintas épocas, se hallan sus aletas, una dorsal provista de grandes espinas en la zona de la cabeza y dos anales. Lo más llamativo del animal son sus dos grandes lunares oscuros, casi perfectamente circulares, ribeteados de un tono dorado, y situados simétricamente en cada costado. El color del animal, en cambio, como suele ocurrir entre los peces, es más difícil de precisar ${ }^{10}$. Concretamente hoy se define como «gris sucio o marrón, con reflejos dorados», o bien como «amarillo o pardo dorado», según las respectivas bases de datos Ictio-term y Asturnatura, s.u., mientras la celebérrima Wikipedia lo ve «oliva-amarillo». Y, sin embargo, es del color $-\mathrm{y}$ no exactamente del amarillo, que es el común a las tres clasificaciones actuales citadasde donde se ha postulado la motivación que habría dado lugar al término latino faber.

Este nombre seguramente es un calco del griego $\chi \alpha \lambda \kappa \varepsilon u ́ c$. Pero las fuentes latinas no dicen nada al respecto, ni siquiera los autores que más espacio le dedicaron a esta especie, como Columela y Plinio, de acuerdo con una manera de entender que sólo cuando se transcribía un término griego se estaba utilizando la lengua griega. Tal silencio hace difícil establecer qué términos concretos son realmente calcos -alrededor de 50 ó 60 en estimaciones aproximadas-y cuáles pueden ser fruto de una coincidencia; más aún, si no hay total correspondencia de significados entre las dos lenguas, como aquí sucede, por la mayor amplitud o menor concreción del término latino con respecto al griego.

Así, al buscar la correspondencia entre los dos términos del binomio $\chi \alpha \lambda \kappa \varepsilon u ́ \varsigma$ - faber, no se halló una solución unívoca: obrero del cobre o del bronce -acaso, 'calderero'-, del hierro - 'herrero / forjador'- o del oro - 'orfebre'-. En la lengua latina estas opciones se precisarían mediante genitivos o adjetivos, según en qué contextos -faber aerarius, ferrarius-, por lo que, en su acepción de ictiónimo, parecía importante hallar el elemento motivador que explicase el significado. Este se consideró establecido por Saint-Denis, s.u. faber, para quien se trataba de un término cromático, debido al aspecto ahumado del animal, cuyo color era gris con reflejos amarillentos en los costados, lo cual le daba parecido a un herrero ${ }^{11}$.

Su propuesta se convirtió en doctrina común al ser recogida por Ernout-Meillet, DEL s.u. faber 2-. Sin embargo, Saint-Denis, ibid., mencionaba, entre otras, una segunda opinión suya, sin negar la anterior, según la cual también habría que considerar su posible derivación del sonido que emitía el pez, ya observado por Aristóteles, $H A 4.9 .3$, que lo había calificado de $\sigma v \rho \imath \gamma \mu$ ó 'silbido' y citado por Eliano, $N A 10.11$. Si se reparaba en que dicho sonido podía parecer similar al del martillo del herrero cuando golpea regularmente una pieza, se podía encontrar un apoyo más preciso para la motivación del término. Otros advirtieron semejanzas muy diferentes, entre

10 En las fuentes antiguas se menciona a menudo el color del animal, pero, como suele ocurrir entre expertos en una materia que no necesitan dar datos que consideran ya sabidos, no suele precisarse si se trata del color del animal vivo o muerto, el de una parte o el de todo él, ni los posibles cambios según el lugar o la época de captura. A ello se suman las discoincidencias de los campos cromáticos del latín y otras lenguas. Por eso, aunque el color constituya un detalle importante en el origen de los ictiónimos, difícilmente se percibe el matiz concreto. De ahí que no extrañe que a la especie en cuestión posteriormente se le hayan dado en la lengua popular nombres tan dispares, tomados del color, como 'gallo blanco'/ 'negro'/ 'verde', según las zonas, cf.infra.

11 También Isidoro (Et.19.6) presenta un texto notable sobre faber, no en su acepción de ictiónimo sino en su significado de 'herrero', que considera el originario, del que derivan las demás acepciones, precisadas mediante los adjetivos que se refieren a los oficios correspondientes: Faber a faciendo ferro nomen inpositum habet. Hinc deriuatum nomen est ad alias artium materias fabros uel fabricas dicere; sed cum adiectione, ut 'faber lignarius' et reliqua, propter operis scilicet firmitatem. 
el sonido del pez y el cacareo del gallo, lo que significaba, en realidad, explicar la designación 'gallo' de una manera también motivada, o bien podía recordar al gruñido del cerdo, de donde le vendría el sobrenombre de 'cochino', en Canarias (Alvar 1989, mapa 618), o al resoplido de un fuelle de fragua (Capponi 1972, 469). Otros propusieron, con mucha imaginación, que en el esqueleto del pez se hallaban todas las herramientas de un herrero.

Esta última propuesta fue entre antiguos filólogos la más empleada. La hemos hallado ya, en primera versión, en una monografía breve debida al humanista francés Pierre Gilles titulada De Gallicis et Latinis nominibus piscium Massiliensium ${ }^{12}$, en la que el autor señala, como dato de autopsia, que encontrándose en Dalmacia, donde continuaban llamándolo 'fabro', le habían dado la explicación de que supuestamente se hallaban en el animal omnia instrumenta fabrilia ${ }^{13}$. Reaparece más tarde la misma etimología en la antigua traducción castellana de Plinio debida a Huerta (1603), quien anota igualmente la permanencia en Dalmacia del término 'fabro', y añade «que significa 'oficial', porque se hallan en él todos los instrumentos necesarios para qualquier oficio».

El traductor de Plinio más puntilloso en este punto, Jerónimo de Huerta, que había introducido en el castellano el ictiónimo zaeus en la forma 'ceo', aceptada hasta hoy, impulsó la transcripción correcta 'fabro'. El mismo vocablo había sido ya empleado por el anterior traductor, Francisco Hernández, sin bien en la forma más tosca 'fáber'. Pero la explicación del término se debe a Juan de Pineda en los Diálogos de la agricultura cristiana, p. $273^{14}$, una obra publicada pocos años antes en la que incluía una aclaración al respecto erudita y certera ${ }^{15}$, fuera del ámbito de la ictionimia -cuando algunos diccionarios de la época y posteriores, como veremos, estaban lejos de dar alguna-. Y, así, indica a propósito del oficio de san José: «El glorioso Sant Matheo dice que le llamaban 'fabro', que quiere decir propriamente (según Suidas), oficial de martillo en materia dura, cuales son carpinteros, herreros, plateros, cerrajeros, canteros y otros semejantes; mas no determina de cuál oficio haya sido». Y, unas líneas después, menciona nuevamente el mismo término a propósito de Cristo, que habría ejercido «el oficio de 'fabro' ... que es oficial». Estas son las referencias fechadas más antiguas del término, pues la traducción de Hernández se data sólo por aproximación y la de Huerta es posterior a estas noticias.

Por otra parte, también la correcta adaptación castellana de faber en 'fabro' pasó a tener un lema propio en los diccionarios. Algunos de ellos, desde el de 1787, ofrecían

12 Presentada con el nombre del autor latinizado como Petrus Gyllus (c.1489-1550) ofrece 120 capítulos breves con perspectiva novedosa por la importancia concedida a la información oral, recogida directamente y contrastada con datos, sobre todo, de los autores técnicos antiguos. Iniciada por una Carta dedicatoria, acompaña como complemento final, en pp. 543-598, a la edición de Eliano, traducido al latín con amplias accesiones.

13 Ibid. p. 557 Dalmatae etiam hac aetate, Fabrum: qui, cum ex eis percunctarer cur sic nominarent, mihi pulchre responderunt, se ideo ita nuncupare, quod omnia instrumenta fabrilia in ipso reperiantur: quod quidem ipsum statim uerum esse periclitatus sum.

14 El franciscano, Juan de Pineda, escribe esta miscelánea, de anécdotas y curiosidades, en forma de diálogo con despliegue llamativo de erudición (1589). Va precedida de un catálogo de fuentes, que incluye «quasi setecientos autores» del ámbito eclesiástico y del mundo clásico. Menciona incluso a Catón y Varrón -como es normal en la época, no da muestras de conocer directamente la obra de Agricultura de ninguno de ellos-cita a Columela y a Plinio, y no da indicios de conocer la obra de Paladio. Ciertos temas agrícolas tienen un papel importante -la viña, el trigo, el aceite, la miel, etc.-, pero por su carácter paradigmático o simbólico. No se trata pues, pese a su título, de una obra de agricultura, más bien de cultivo del espíritu virtuoso cristiano.

15 Precisión similar a la del TLL, s.u., que indica que puede referirse con carácter general a quilibet artifex qui materiem duram (uelut metalla ligna lapides ebur) tractat. 
un significado muy general 'pez marino', remitiendo al lema 'ceo'. Desde finales del s.XIX (1884) a la fecha actual se ofrece la equivalencia 'artífice'. Pero, curiosamente esta palabra se ha cargado de nuevos matices, alejados de los que ofrecían anteriormente otras, como 'artesano', 'oficial', 'menestral', y ya no sirve para traducir el pasaje de Plinio - ni el de Columela- que la habían motivado.

A la postre, el pasaje de Plinio, en la época en que sus ediciones, traducciones y comentarios atestiguan su mayor autoridad, junto con la mención de Columela, supuso la incorporación al castellano de dos términos nuevos, dotados de un lema propio en los diccionarios, pero de muy poca o nula vitalidad en la lengua española ${ }^{16}$. Tampoco en la lengua latina habían tenido un uso extenso. En la amplia recopilación de términos latinos de la antigüedad tardía y medieval de Du Cange ya no se registran -incluso en el lema faber en su acepción de ictiónimo hay una remisión que conduce a sus otros nuevos nombres citula y aurata-. Puede por eso decirse que su presencia está limitada a ciertos autores clásicos del ámbito de la erudición, tanto en el caso del grecismo zaeus, utilizado como tecnicismo estricto, cuyos restos se limitan a los autores y pasajes citados, al igual que en lo que respecta a faber en su especialización como tecnicismo ictiológico, aun siendo un término de uso amplio en la lengua común.

\section{Los nombres populares hispanos}

\section{El ictiónimo 'gallo'}

Aparte de los nombres 'ceo' y 'fabro', de clara procedencia culta, hay otros populares en España con distinto grado de uso; entre ellos, 'gallo', 'pedro' y los distintos compuestos: 'pedrogallo' / 'gallopedro' y 'sampedro'. Hoy este último es el más empleado, el único considerado oficial desde el punto de vista comercial, ${ }^{17}$ reconocido como tal por el Diccionario de la Academia ${ }^{18}$.

Por su uso en España y su presencia en otros puntos del área romance '(sam) pedro' y también 'gallo' son las dos denominaciones más representativas de la serie. Ambos son nombres motivados. En este último, metafórico, la motivación semántica subyacente (González 2008, 308) descansa en la morfología del animal, cuyo parecido con el ave homónima ya había sido subrayado tradicionalmente, al estar

16 En la base de datos CORDE, s.u. 'fabro', del total de nueve sólo tres coincidencias, incluyendo la debida a Pineda, permiten ver la débil entrada de este término en la literatura-las demás no son castellanas, o son alteraciones de fablare, etc.- Aun siendo escasas y alejadas de la ictionimia, testimonian un cierto grado de vitalidad literaria de la que carece 'ceo'.

17 Así se observa en el Listado de denominaciones comerciales de especies pesqueras y de acuicultura admitidas en España-BOE 15 junio 2019, sin modificación en la actualización del año siguiente- en el que se ofrece la denominación oficial 'pez de San Pedro' junto a otras, prioritarias en distintas zonas: 'gallopedro' (Andalucía, Murcia), 'gall de sant Pere' (Cataluña y Baleares), 'gallo san Pedro', 'barbero' (Canarias).

18 No se anotan diferencias zonales fonéticas - pez (/peje/ pehe); gallo (/gayo)-; sobre ellas, cf. Alvar 1970, 188189; Garcés 1993, 179ss. y Arias-De la Torre 2019, 246-248. Entre las variantes documentadas 'sampedro', 'sanpedro','pez (de) san Pedro', 'san Pedro', preferimos la primera de ellas, más común. Utilizamos los términos 'gallo', 'gallopedro', 'pedrogallo', ‘pedro' y la lexía 'gallo san Pedro', aun no estando recogidos en el Diccionario de la RAE o sólo de forma incompleta. Así, 'gallo', como ictiónimo, en DRAE se refiere al Lepidorhombus, más usual, pero ya no a la especie piscícola Zeus faber L. aquí tratada; con respecto al resto de las denominaciones, sólo recoge 'pez de san Pedro', bajo el lema 'pez'. Más allá de los resultados hispanos aquí contemplados, en la totalidad del contorno mediterráneo, Cortelazzo, pp. 16-26 registra 24 denominaciones y señala la extensión de 'gallo' por la zona vasta, pero homogénea del Mediterráneo occidental, con expansiones fuera del dominio romance. 
dotado de la citada aleta dorsal de grandes radios y de aleta ventral, similares respectivamente a la cresta y a las llamadas barbillas del gallo de corral. Este detalle y acaso otros, como su boca protráctil y ojos simétricos en ambos lados, le otorgaban un parecido incluso mayor al ave que el que se atribuye al pez que hoy se conoce, con mayor generalidad, como 'gallo' - del grupo Lepidorhombus, también llamado, según las zonas, 'rapante', 'palaya', 'lenguadina', etc. ${ }^{19}$-.

Al tratar de reconstruir la historia del término, se observa que en el latín escrito de toda época no hay rastro de la utilización de gallus -ni gallina-como ictiónimo ${ }^{20}$, aunque sabemos que posteriormente tuvo gran frecuencia y extensión. De hecho, a pesar de que hoy es un nombre que va perdiendo uso en la designación de esta especie piscícola, la situación actual, descrita en trabajos de Geografía lingüística, muestra que quedan todavía sus huellas en Italia, 'pesce gallo', persistiendo en Roma como término local, así como también se halla esporádicamente en el área sur y a lo largo del Mediterráneo occidental, donde se registran 'gallu' en Córcega, 'gal(1)' en Sicilia, oc, catalán, así como 'gallo' en la zona levantina española con continuidad en Murcia, Andalucía incluida su vertiente atlántica, Canarias y también en Portugal, 'peixe galo' (a partir de los datos de Cortelazzo, Alvar y Arias-De la Torre). En Francia se emplea ocasionalmente 'poule de mer', acaso un calco que influyó en el nombre de 'gallineta', catalanismo utilizado en la traducción de Columela al castellano por Álvarez de Sotomayor $(1924,2,36)$ y en otras posteriores. De acuerdo con esta distribución, se observó la mayor presencia y concentración del término 'gallo' en el sur de España, siguiendo en una línea ininterrumpida por la costa mediterránea hasta los enclaves citados del mediterráneo. Ello permitía suponer que este ictiónimo era hispano (Cortelazzo, pp. 19-20) y que la expansión de este término se produjo desde estas zonas hacia el Mediterráneo oriental.

No obstante, desde el ángulo diferente que proporcionan los textos sobre ictiología de los humanistas se comprueba que 'gallo' no solo es nombre hispano, sino también el que se hallaba entonces en la zona atlántica sudoccidental de Francia, al norte del Garona (Santones) y también sur de su desembocadura (Baionenses), abarcando el golfo de Vizcaya (para el resto de Francia, excluida la zona de Marsella, la denominación principal es 'dorada/(e)' sin la menor referencia en estas obras a la advocación a san Martín).

De ahí se infiere que el término 'gallo' retrocedió hasta ser desplazado de estas zonas por la expansión del nombre de 'sanmartín' a lo largo del camino de Santiago. Y ello permite suponer que en el resto de España corrió una suerte similar al ser desplazado por el nuevo término 'sampedro', de forma que los abundantes restos occidentales de 'gallo' - portugueses aparte de hispanos-, más que significar un punto de irradiación, representan, en nuestra opinión, los restos antiguos de un arrinconamiento por la llegada de otros términos de carácter religioso, ayudados por condicionamientos importantes de carácter lingüístico.

19 Y, probablemente, por la posición de sus ojos en un mismo costado, en gallego, catalán y zonas del Cantábrico se le da el nombre de 'meiga', 'bruixa', 'ojito'. Hay especies similares y no siempre distinción terminológica clara dentro del grupo Lepidorhombus.

20 No se contempla tal uso en textos latinos en los que se trata de homonimia, ni siquiera cuando esta se ejemplifica con las distintas acepciones de gallus, entre las cuales no figura su posible empleo como ictiónimo. Así, en Quintiliano Inst.7.9.2: Singula adferunt errorem cum pluribus rebus aut hominibus eadem appellatio est ('homonimia' dicitur), ut gallus, auem an gentem an nomen an fortunam corporis significet, incertum est. Sobre estas últimas acepciones, que tienen como referente más antiguo el ave doméstica, $c f$. Mata Oroval 2015, 54-264. 
En efecto, muy probablemente en el proceso de desplazamiento y tendencia al desuso del término 'gallo' en favor de 'sampedro' tuvo importancia el hecho de que aquel servía también para designar otra especie más abundante entre pescadores y usuarios, y más comercial, la que se quedó finalmente con el nombre 'gallo' -identificada hoy por los naturalistas, en un grupo diferente, como Lepidorhombus whiffiagonis, a la que poco antes hicimos referencia y emparentada con otras especies como el Lepidorhombus boscii, también de consumo general y, como la anterior, designada popularmente con el mismo nombre y con otros varios de carácter local-. En definitiva, supuso una forma de evitar la llamada homonimia 'de proximidad', como la que podía darse entre el Zeus faber y estas especies, diferentes de él, pero mucho más próximas entre sí y más comunes entre la gente.

De otra parte, en el proceso de diferenciación entre las dos especies principales portadoras del mismo nombre, el 'gallo' (Lepidorhombus) y el 'gallo' (Zeus faber), uno de los caminos recorridos para su distinción consistió en la determinación ulterior del segundo de los citados mediante procedimientos léxicos especialmente, añadidos al elemento -ga1lo-. Así cabe explicar, y entender como designaciones posteriores, las amplificaciones por yuxtaposición 'gallopedro', 'pedrogallo' y las explícitamente cristianizadas 'gallo de la Pasión' y 'gallo san Pedro', de las que luego trataremos ${ }^{21}$. Se hallan también otras mediante el empleo de adjetivaciones de color -'gallo verde / negro'-; además, determinaciones referidas a sus marcas circulares -'gallo de la pinta / de la pintita / pintado / del lunar', 'ojogallo'-, al parecido de su aleta ventral con una barba -'gallo barbero'-e incluso algunas designaciones con procedimientos sufijales -'galludo', 'gallineta'-.

En otras palabras, el animal percibido como más característico resultó ser lingüísticamente el más caracterizado frente a la especie considerada más general. Es el mismo procedimiento que se puede observar en el que se estima que es otro representante de la misma familia de los Zeidos, el Zenopsis conchifer, considerado de calidad muy inferior como alimento y menos valorado comercialmente que el 'sampedro'. Lingüísticamente se ha diferenciado tomando a éste como referencia por el mismo procedimiento de la adición de más adjetivos - 'pez de San Pedro plateado', con adjetivo final alternante con 'blanco / basto / bravío'- y otras determinaciones - 'gallo de mala casta / de fuera', etc.-.

En suma, el éxito final de la designación 'sampedro' tenía la ventaja de lograr cierta univocidad frente a las citadas variantes, reducidas hoy a sinónimos de menor vitalidad.

\section{El ictiónimo '(sam)pedro'}

Se acepta lógica y razonablemente que 'sampedro' es una remotivación al abrigo de uno de los relatos que acompañan a San Pedro pescador. No se cuestiona que se trate de un antropónimo. Los aspectos que se cuestionan son cuándo, dónde y por qué se utilizó concretamente el nombre de este santo, difundido, hasta ocupar parte del lugar que tenía 'gallo' con anterioridad a su llegada.

En lo tocante a este último aspecto, en el trabajo señero de Migliorini (1927, 124, 230, 241), aunque no se hace referencia al ictiónimo, se citan algunos momentos de

21 Por este mismo procedimiento cabe explicar, en nuestra opinión, designaciones como la señalada por Garcés (1993, 179) en Chipiona donde se distingue 'gallo' (Lepidorhombus) y 'pehegayo' (Zeus faber), otra amplificación por yuxtaposición. 
la vida de San Pedro - pescador, fecha de su festividad, poseedor de las llaves del cielo- que habían desembocado en la creación de nombres comunes. En esa línea, se defendió (Giammarco 1963-64, 217) que la festividad del santo había originado el ictiónimo, al coincidir con la época de mayores capturas pesqueras, a semejanza de otra de las denominaciones del pez, la de 'sanmartiño / sanmartín' en gallego y zonas del norte, que también se había considerado tradicionalmente derivada de la festividad del santo, San Martín en este caso, y por las mismas razones. Pero la distancia entre las festividades de los dos santos, el 29 de junio y 14 de noviembre, suponía un arco temporal demasiado largo e incluso contrapuesto para ser época pesquera de la misma especie y, en consecuencia, un grave inconveniente (Arias-De la Torre 2019, 247) para esta hipótesis ${ }^{22}$.

Del mismo estudio de Migliorini podía desprenderse otra explicación, basada en la capacidad del ictiónimo 'gallo' para desarrollar, por simple asociación de ideas, nombres relacionados con la figura del Apóstol ( $c f$. nota 28). Pero obra en su contra el factor de la discoincidencia de cronología entre este término más antiguo y el que lo desplazó, además de las distintas zonas de presencia de cada uno.

Tampoco se halla una explicación del todo convincente tomando como punto de partida originario la variante no hagiográfica 'pedro'. En línea con esta posibilidad, en un texto de las Haliéuticas, vv.109-110, el fabro ( $\chi \alpha \lambda \kappa \varepsilon ́ \alpha)$ es calificado de saxáti123:

Tum uiridis squamis, paruo saxatilis ore et rarus faber

También está situado con los peces que nadan entre las piedras por Opia-

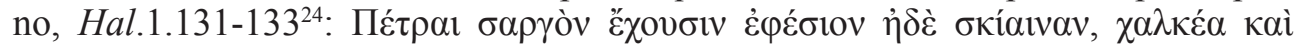
коракі̃vov.

Precisamente saxatilis representa, como calco, la traducción literal latina del

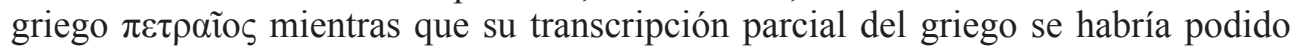
especializar como nombre del animal, de forma que representaría una de las muchas supervivencias de términos griegos en el mundo romance ${ }^{25}$. En el ámbito latino hay pruebas de que había conciencia clara de la interrelación de los términos, como se

22 Además, en el folclore, especialmente en refranes, se han observado algunas relaciones entre una festividad y la época de mayor o menor captura pesquera de una especie, pero no hay documentación de que la fecha de un santo haya originado el ictiónimo correspondiente

23 Saint-Denis $(1947,100)$ señaló que saxatilis se refería en este pasaje, como en el texto de Opiano, al Zeus faber L., cuestión que nos parece clara también porque, según convenciones retóricas, se califica triplemente con adjetivos referentes al color, al hábitat y a sus costumbres solitarias, o sea, uiridis, saxatilis y rarus. Sin embargo, advirtió el problema que representaba la lectura de los manuscritos parvo ore, al caracterizarse el animal por una boca grande y protráctil. En cambio, Capponi (1972, 468ss.) propuso una puntuación diferente del pasaje para evitar este problema, independizando el verso et rarus faber del anterior. La enmienda al texto, propuesta por Baltar $(1975,81)$ prauo ore, nos parece que soluciona el texto entendiendo «saxátil de boca atravesada».

24 También en la traducción al latín por el humanista Konrad Rittershausen, del citado pasaje de Opiano, ibíd.: Petrae sargum tenent familiarem atque sciaenam fabrumque.

25 Battisti (1960-1, 63) acepta la estimación de unos 200 ictiónimos griegos pasados al latín y, en torno a 60, que podían haber llegado, por medio del latín o bien directamente, a las lenguas neolatinas, apareciendo a veces como calcos en las lenguas actuales, de forma que el léxico de la ictiología actuó como uno de los grandes impulsores de grecismos: la ittionimia latina risente moltissimo di quella greca. En este caso, la transcripción parcial implicaría la sustitución del adjetivo griego por un nombre apuesto, habitual en las designaciones de peces. 
aprecia en la explicación etimológica ofrecida al inicio del pasaje citado por Columela (8.16.7):

Rursus optime saxosum mare nominis sui pisces nutrit, qui scilicet quod in petris stabulentur saxatiles dicti sunt.

La falta de atestiguación temprana del ictiónimo representa un problema de la propuesta, mientras en su continuidad conecta con la denominación '(pez) pedro', conservada en España en zonas de Levante (Arias-De la Torre 2019, 245), base de los compuestos hispanos posteriores 'pedrogallo / gallopedro'. Está también presente, como 'pesu pedru' y 'pesce pietro', en las costas italianas del Tirreno, y en otros puntos del Mediterráneo. En la parte oriental, de influjo helénico, se halla la denominación $\pi \varepsilon \tau \rho o \psi \alpha ́$ óos, mantenida en Chipre para designar esta especie piscícola (Cortelazzo 1965, 22, 607) y en otras partes, para la designación de esta u otras, tal como se recoge en el glosario griego de Du Cange, s.u.; por último, en lenguas actuales se halla por vía de préstamo ${ }^{26}$. Tal denominación del animal respondería a las características del hábitat o del lugar de la captura, lo cual es una de las causas concretas que obran dando lugar a la creación de ictiónimos motivados, dentro de las establecidas para la ictionimia latina (Saint-Denis 1947, XXIV).

A diferencia de los problemas del origen, sobre la época de la llegada a España del término hagionimizado podemos hablar con cierta seguridad, ya que tenemos noticias de interés en la primera traducción de Plinio el Viejo. Allí Francisco Hernández informa de la existencia de la designación italiana 'Sant Pietro' para este animal, que por entonces era llamado 'gallo' en España. Fiel a su criterio de no traducir los nombres técnicos, sino transcribirlos y comentarlos, traslada las denominaciones del pez como 'zeus' y 'fáber'. Pero, en una de las notas al pasaje - «El intérprete, 2 Fáber»- señala con respecto a los nombres: «Llaman este pesce en Roma pesce de Sant Pietro, y en Hespaña, con nombre común a muchas otras naciones, pesce gallo». La traducción de la Historia Natural parece que estaba avanzada cuando Hernández, para concluirla y profundizar en la farmacopea mediante el examen de las hierbas americanas, partió para Nueva España hacia 1570, que nos sirve como fecha aproximada de esta noticia que, lógicamente y dada su procedencia europea, Hernández conocería antes de su partida.

Es este, por lo tanto, un testimonio explícito del conocimiento de los dos ictiónimos y de su uso para la designación específica de esta especie en España, aunque sólo aparezca en una nota explicativa y como préstamo. Anteriores a ésta son otras referencias al Zeus faber, propias de la bibliografía ictiológica de los humanistas, que sitúa la designación dedicada al Apóstol exclusivamente en Roma y el término 'gallo' en un área occidental que incluye España, ambos en la misma época.

Una de las primeras atestiguaciones se halla en la breve monografía De Romanis piscibus de Paolo Giòvio (1531, 99), considerado el precursor de los estudios de ictiología de su época, en donde indica que pesce San Pietro era la denominación dada por romanos y venecianos; no por genoveses. No mucho después Pierre Gilles $(1533,557)$ en el capítulo titulado De fabro recogía hasta diez nombres antiguos y actuales siguiendo una dirección este a oeste, desde Grecia hasta España: Romani

26 También, otras leyendas cristianizadas, como la de San Cristóbal, que habría agarrado al pez mientras cruzaba el río (o el mar) llevando al Niño Jesús, sustentaron denominaciones como la actual griega $\chi \rho ı \tau \tau$ ó $\alpha \rho \circ$, que ya llamó la atención de humanistas, como Gilles, cap. XLII, Belon, p. 150 y Rondelet, p. 329. 
uocant piscem Sancti Petri siue Situlam ... Hispani nuncupant Gallum. Es un dato que se repite con alguna información nueva en obras como la de Belon $(1553,150)$, al añadir que, en Roma además de este nombre tenía también el de cetola-/citula-, que era el popular habitual, lo que parece confirmado por las variantes fonéticas con las que se cita (situla/cetola/citula) frente a la inamovilidad del término hierático, que se presenta así como una superposición posterior. A su vez, los humanistas mencionan 'gallo' como término metafórico, propio de los Hispani, Santones et Baionenses (Rondelet, p. 329; Salviani, p. 204; Gessner, p. 440).

Estos datos tienen también validez para establecer la cronología al complementar menciones más antiguas, pero muy poco relevantes, para fijar la época en que el ictiónimo 'gallo' y sus afines sirvieron para designar concretamente esta especie piscícola. Por ejemplo, se puede observar que el término 'galludo' está atestiguado como ictiónimo al menos desde el año 1400, pero no hay seguridad en su identificación en la época, aunque todavía hoy sea ese uno de los nombres del Zeus faber. Un ejemplo similar (de acuerdo con los datos de CORDE) de presencia del ictiónimo 'gallo', pero sin seguridad en el referente, se encuentra en la obra de Estéfano de Sevilla, datada ese mismo año (Sánchez 2004). Tampoco llegan a ser precisas, en la indicación de la especie de referencia, las informaciones procedentes del Diario de Colón (Alvar 1976, I,157) y de las Ordenanzas municipales de Málaga y Granada de 1501 (Arias-De la Torre 2019, 248), en las cuales se ha documentado también 'gallo' como ictiónimo, pero empleado como designación general, sin que permitan saber tampoco a qué animal concreto hacen referencia ${ }^{27}$.

La procedencia italiana del término 'sampedro', que se subraya en los textos de Giòvio, de Gilles y, por extenso, de otros humanistas, así como en el de Hernández, también es coherente con la gran concentración de este ictiónimo en Italia e islas adyacentes hasta tiempos actuales. De otra parte, el testimonio de Francisco Hernández, que muestra conocer el término italiano en la anotación, sin utilizarlo en el texto, es prueba de que la mención del santo no se empleaba en España para este referente. Tampoco 'gallo' debía de parecer apropiado, creemos que por su carácter metafórico, popular, para la traducción de ninguno de los dos términos que aparecían en el texto de Plinio. Aún después, en la traducción de Jerónimo de Huerta (1603) son nuevamente, como ya se ha dicho, las transcripciones correctas 'ceo' y 'fabro' las únicas que aparecen.

\section{Textos y leyendas cristianas en la remotivación}

Entre los nombres cristianizados, uno de ellos se basa en el relato quizás más conocido de la vida de San Pedro, cuando renegó tres veces de Cristo, a pesar de su advertencia, antes de que cantara el gallo. Esta narración sobre la debilidad humana

27 Las referencias son escuetas y generales. Las Ordenanzas de Málaga ofrecen el término nudo en una relación de peces. Así también aparecen reiteradamente otras en el Diario de Colón, en las que se señala que se pescaron «muchos pescados como los de Castilla (/ España)», mencionando entre ellos los 'gallos'. En una de las pocas que contiene alguna descripción, figura 'gallos' en un símil designando no una sino varias especies de aspecto similar: «Aquí son los peces tan disformes de los nuestros, ques maravilla. Hay algunos hechos como gallos de las más finas colores del mundo, azules, amarillos, colorados y de todas colores».Muy posterior a la de F. Hernández es una mención de interés en el manuscrito de Pehr Löfhing, Pisces Gaditana (sic!: probablemente por puntuación defectuosa y omisión del término nomina). Observata Gadibus et ad Portus $S^{a}$ Maria 1753, con las dos denominaciones de 'gallo' y 'pes de San Pedro'. En los diccionarios aparece por primera vez 'gallo' en la acepción 'pez' en el de 1734. 
y el perdón aparece en todos los Evangelios (Matth.26.34; Mar.14.30; Luc.22.34; Ioh.13.38), hubo de ser el centro de muchas homilías, pero solo tuvo reflejo en una designación hispana, local (Alvar 1970, 189) y poco duradera, como 'gallo de la Pasión'28.

Las denominaciones 'gallopedro' y 'pedrogallo' presentan el elemento común -pedro-, el mismo que, como nombre individual y concreto, está testimoniado en el ictiónimo 'pedro'. Pero no muestran una vinculación explícita con la figura de San Pedro. Si alguna vez la hubo, quedó desdibujada al formar sendos compuestos por yuxtaposición sin espacio entre los dos miembros. En 'pedrogallo' sería más fácil suponer la asociación con el santo, según el uso habitual del castellano (Iglesias 2015, 88) donde la combinación característica implica que el nombre del santo aparezca o bien como primer elemento o sólo precedido por antenombre átono; pero este tipo de formación es muy escasa y carece de paralelos en la serie de ictiónimos, por lo que más bien debería ser interpretada como una variación, estrictamente local, del otro término trastocando el orden de sus elementos.

En efecto, 'gallopedro' resulta una formación de mayor regularidad, en la que parece razonable ver que su segundo elemento es una especificación o concreción del primero, el general o dominante, similar a la de otros términos de esta serie, como 'gallocristo' y, similar a la formación más extendida 'pez gallo' (o 'pejegallo' con sus variantes derivadas, que excluyen siempre el cambio de posición de los miembros, dispuestos en orden categorial del más general al más concreto). De la vitalidad de este compuesto, manteniendo la primacía de 'gallo', dan muestra otras denominaciones hagionimizadas y con otras adiciones, como 'gallo (de) san Pedro' (o 'gallo sampedro').

No obstante, al deseo de buscar una asociación con el santo responde una leyenda superpuesta, documentada en el sur de España (Cortelazzo 1965, 23 la recoge en Málaga), basada en una etimología popular que resulta especialmente bien ajustada para explicar la etimología de 'gallopedro', ya que había sido el propio Cristo quien, al recoger la red y contemplar las capturas, pronunció las palabras que iban a convertirse en el nombre exacto: « iun gallo, Pedro! $»^{29}$.

Otra narración de tenor muy diferente, por su carácter menos conocido, se considera que sirvió de base al ictiónimo 'sampedro'. En el Evangelio de Mateo,17.24-25, se lee que preguntaron a Pedro si el Maestro pagaba las dos dracmas de un tributo para el mantenimiento del templo. Pedro respondió afirmativamente, pero quiso cerciorarse con el Maestro. Y este, antes de ser preguntado por Pedro, se anticipó a hacerle saber que ellos estaban exentos de ese pago. Sin embargo, para no escandalizar, le mandó salir a la mar y coger el primer pez que picara el anzuelo, en cuya boca

28 La relación de San Pedro con el canto del gallo propició incluso la remotivación de topónimos como Gallocanta / Gallicant / Cantagallo / Canta el Gallo, cuyo origen etimológico se considera hoy celta e independiente por tanto de este famoso episodio de los Evangelios. Pero, sin embargo, fueron reinterpretados popular y cristianamente de acuerdo con él, y las iglesias y lugares de las proximidades pasaron a estar bajo la advocación del santo.

29 Este tipo de leyendas etimológicas populares se basan en el orden de los miembros de una palabra, que motiva por asociación los de una frase explícita y aclaradora que, manteniendo el mismo orden de la palabra, descubre el significado de esta, como en una especie de acto de lectura lento y reflexivo. La etimología suele ir acompañada de una explicación anecdótica de un suceso puntual. Por ejemplo, en toponimia, con uso también de vocativos: Ataquines («ata aquí, Inés», habría pedido la reina Católica a una doncella), La Bañeza («lava, necia», habría dicho un hombre reprendiendo a una lavandera [mora] que trataba de escuchar su conversación). En otras versiones, más largas, de la leyenda aquí aducida se cita: «un gallo, Pedro, un gallo», palabras ad hoc para justificar tanto 'gallopedro' como 'pedrogallo', aunque esta última más dificultosamente -'un'-). 
hallaría una estatera para pagar el impuesto por los dos. Y, hasta aquí, el milagro narrado de modo inconcluso por San Mateo, que no añade ningún dato sobre el cumplimiento del mandato de Cristo frente a lo que suele esperarse en textos relativos a milagros, ni tampoco sobre el desarrollo ulterior de la historia narrada. Así que hubo de imaginarse, como final popular del relato, que San Pedro, cumpliendo la orden, agarraría al pez dejándole impresas las marcas de sus dedos, un detalle que no consta en el pasaje evangélico, pero constituye la base popular de la etimología.

En las exégesis de Orígenes, frg.373, y, en el mundo latino, en los comentarios al pasaje de San Hilario y San Jerónimo (Comm. in Matth., ad l.; SC 258,73ss. y 259.3.42ss.) se interpretó el milagro en sentido alegórico, especialmente el pez que figuraba en él ${ }^{30}$. Ninguno de los comentaristas mostró interés en la identificación del pez como tal, pero sí, en cambio, se anticiparon a señalar otras cuestiones controvertidas del pasaje planteando el interrogante de si se trataba de un milagro de presciencia o de poder y, sobre todo, en la línea de Jerónimo, trataron de justificar aquel hecho milagroso que, entendido en sentido literal, se debía a simples razones tributarias. Otros autores ahondaron en el carácter innecesario de dicho milagro doble, que sólo refería Mateo, quien curiosamente antes de evangelista había sido recaudador de impuestos ${ }^{31}$.

Dudas diferentes, a propósito de la veracidad del relato, asoman ya en los textos de los humanistas que ofrecen el nombre del pez 'sampedro'. Algunos, como Pierre Gilles, sugieren el antiguo carácter sacro como causa de su cristianización, al incluir el dato de que antes había estado dedicado a Zeus y, en su época, llevaba el nombre de Christopsaron ${ }^{32}$. Otros, aunque fueron de los primeros eruditos en señalar que el nombre se basaba en el citado pasaje del Evangelio y en dar los detalles de la pesca milagrosa y la moneda en la boca, sin embargo añadieron a su explicación elementos distanciadores, como ferunt -Gessner, p.439 citando a Rondelet p.329-, credatur -Salviani, p.204-, fortasse-Belon, p.150-, dejando claro que dudaban del soporte de la etimología en la leyenda que narraban, lo cual hace sospechar que ellos encontraron y explicaron un nombre cristianizado previamente, que no partió de su círculo.

Fue mucho más tarde cuando se sumaron interpretaciones racionalistas enfocadas a la identificación de la especie, que aseguraron que el animal pescado por San Pedro era imposible que fuera éste, ya que la narración se situaba en Cafarnaúm, en la orilla occidental del mar de Galilea o lago Tiberíades, de agua dulce, donde abunda el 'pez peine', pero difícilmente se hallaría un animal de mar.

En suma, a diferencia del pasaje del Evangelio sobre la renegación de San Pedro, este es un texto más rebuscado, documentado en uno solo de los evangelistas, de interpretación discutible en círculos cultos y difícil de emplear en la predicación. Sin embargo, esta justificación erudita y rebuscada narraba una pesca milagrosa con la intervención de un santo, un tipo de relato llamado a tener difusión. Hemos en-

30 Se consideraba alegóricamente el infiel hundido en las profundidades. En la misma línea de Orígenes, su sucesor, Hilario, reconocía en el pez al primer mártir y, para Jerónimo, ese primer pez capturado por Pedro, que moraba en el fondo del mar y en su agua salada y amarga, era el trasunto -secundum mysticos intellectus- del primer Adán, que sería liberado por Cristo como segundo Adán.

31 Por ejemplo, San Jerónimo, ibíd., subrayó como principal milagro la presciencia del Maestro, pues sabía de antemano qué habían preguntado los recaudadores, como también que el primer pez en picar el anzuelo llevaría una moneda en la boca. Pero Jerónimo contempla la posibilidad de que el segundo milagro no fuese de presciencia, sino de poder, de modo que la palabra del Maestro originase la aparición de la moneda.

32 Ibid. p.557: Zeus siue faber figura orbiculata ... nunc in templis suspendunt et Christopsaron ideo arbitror appellant, quia olim Zeus Iuppiter nuncuparetur. Romani uocant piscem sancti Petri... 
contrado una réplica temprana -una de las primeras, según creemos- de una pesca milagrosa que acerca la vida de un santo y la suerte de un pez que, a la postre, estará bajo su advocación, en una de las Vidas de San Martín de Tours, escrita en verso hacia el año 463 por Paulino de Petricordia 5, 654-693. Allí se refiere que, al faltar la pesca habitual para el sustento de la comunidad de monjes, San Martín ordena a un fiel diácono que vuelva al río profetizando una pesca cuantiosa, tal como ocurre cuando saca un gran éxoce al que a duras penas logra agarrar con sus manos. Esta versión contiene cambios con respecto a la del Evangelio en el sentido de que faltan detalles como el de la moneda en la boca o el pago de impuestos, criticados por los ya citados exégetas y ahora sustituidos por una justificación tan comprensible como el hambre de los monjes. Además, se identifica al animal como un éxoce -forzosamente, por la ubicación de la comunidad, tenía que ser un gran pez de río; acaso, un salmón-. Pero, lo más relevante, es que se describe con detalle la dura lucha de los brazos y las manos de quien agarraba a aquel pez resbaladizo para que no escapara ${ }^{33}$. No se llegan a mencionar exactamente las marcas que quedaban en el animal. Pero ahora que se había dicho que al pez lo habían sujetado con fuerza, era mucho más fácil suplirlas en el relato y atribuirlas obviamente al pez que las tenía. En suma, en este relato, culto y en verso, se recogen primeras leyendas, más cercanas a las de tipo popular, en torno al pez protegido en estas zonas por San Martín ${ }^{34}$.

\section{Recapitulación final}

Se ha examinado en las páginas anteriores la doble tradición, latina y romance, culta y popular, del animal identificado como Zeus faber L. Como punto de partida, la vía culta arranca de las dos denominaciones, transmitidas por Columela, Plinio y filólogos posteriores. A partir de los contextos en los que figuran ambas denominaciones, hemos podido observar ciertas diferencias de uso ya en el mundo latino de época clásica. En la Edad Media, la transmisión textual de los términos respectivos en ambos autores avala las formas faber, sin discrepancias y zaeus, un término que por su atestiguación antigua y su transmisión firme por parte de los manuscritos más autorizados, se muestra distanciado del teónimo. Sin embargo, la lectio vulgata de los códices, con su forma zeus, a través de las traducciones a vernáculas, comentarios y ediciones fue la que llegó a eruditos europeos y españoles, dando origen respectivamente al nombre que lo identifica entre científicos y al cultismo 'ceo', cuya llegada aproximada hemos podido datar, así como constatar su muy escasa vitalidad.

Asimismo, por el examen de los contextos de los citados autores clásicos, hemos señalado que faber se había convertido en Roma en el nombre usual para designar este referente, relegando al anterior a arcaísmo; se trataría, en nuestra opinión, de un despectivo, motivación suficiente para designar un producto percibido de pésima calidad en Roma, aparte de los matices concretos del oficio de referencia. Se han

33 La lucha para sujetar al pez se describe ibid.5.676-680 ...Tum toto pectore pronus $\mid$ humida labenti circumdat bracchia pisci| lubrica nudatis uix haeret praeda lacertis $\mid$ concussa et madidis iam paene elabitur ulnis.

34 Bajo la advocación de San Martín, el Zeus faber L. recibe los nombres de 'saint-Martin', 'muxu martin / martintxo', 'sanmartín' y 'sanmartiño', a lo largo del Camino de Santiago, $c f$. n. 2. Sin embargo en ninguno de los tratados de ictiología de los humanistas aquí considerados se menciona ningún ictiónimo relacionado con Martín ni con San Martín. La aparición de este ictiónimo -no así la creación-se documenta con posterioridad a la de San Pedro. 
podido ofrecer también datos sobre la llegada del término 'fabro', ya convertido en término canónico por aparecer en los auctores, y se ha podido poner nombre a los primeros filólogos que se ocuparon de lograr su transcripción correcta (Huerta) y de ofrecer explicaciones sobre su etimología (Pineda), dando lugar a la incorporación de este otro nuevo cultismo al castellano.

Por otra parte, los nombres comunes actuales de esta especie piscícola, entre ellos y como cabezas de serie, 'gallo' y 'sampedro', aparecen en grandes áreas del mundo romance sin mantener un vínculo de derivación desde ictiónimos latinos.

Se ha partido del término 'gallo', reconocidamente metafórico del ave, bien atestiguado en el romance occidental incluyendo el área peninsular. Partiendo de estos datos de geografía lingüística y del examen de textos de los humanistas científicos, traductores unos y autores otros de obras monográficas de ictiología, se ha podido documentar el retroceso, en espacio y en uso, de este término hasta su carácter, hoy residual, para este referente, debido a la competencia con los términos religiosos, como 'sanmartín' y, en particular, 'sampedro', cuya procedencia italiana y datación hemos podido documentar. Desde el punto de vista lingüístico, el retroceso de 'gallo' se vio favorecido por su situación de homonimia de proximidad con la designación de otras especies de mayor importancia comercial, lo que explica su proceso de diferenciación frente a dichas especies mediante su determinación ulterior por distintos procedimientos léxicos y morfológicos, plasmados en una amplia serie de designaciones locales posteriores, en esta y en otras especies piscícolas cuyo nombre responde a los mismos patrones categoriales.

En el caso del ictiónimo 'sampedro', cuya remotivación cristiana no es objeto de discusión, se han revisado las hipótesis y problemas sobre su origen, de los que no está exenta la explicación más sencilla, a partir de la forma simple, no hagionimizada. Y, en el terreno de los datos, se han aportado primeras fechas de la atestiguación de ambos ictiónimos 'gallo' y 'sampedro', y de su presencia o llegada a España para designar concretamente al identificado como Zeus faber $L$. Por último, se han examinado textos del Evangelio y leyendas cristianas relacionadas con ictiónimos, como 'sampedro' y 'sanmartiño', proclives a desembocar en relatos de pescas milagrosas gracias a la intervención del santo que les dará nombre.

\section{Bibliografía}

Alvar López, M. (1970), «Ictionimia y Geografía lingüística». RFE 53,155-224.

Id. (1976), Cristóbal Colón. Diario del Descubrimiento. Estudios, ed. y notas, Madrid, La Muralla.

Id. (1985/9), Léxico de los marineros peninsulares, Madrid, Arco.

Álvarez de Sotomayor, J.M. (2013 [1824]) Los doce libros de Agricultura que escribió en latín Lucio Junio Moderato Columela, traducidos al castellano, Valladolid, Maxtor.

Arias, A.M.-De la Torre, M. (2019), Ictionimia andaluza: Nombres vernáculos de especies pesqueras del "Mar de Andalucía", Madrid, CSIC.

Baltar Veloso, R. (1975), Fauna ictiológica en latín, Tesis doct., Madrid, Univ. Complutense. Barbarus, Hermolaus (1495[1492 Roma]), Castigationes Plinianae. Cremona, C. Darlerius. Barriuso Fernández, E. (1986), El léxico de la fauna marina en los puertos pesqueros de la Asturias Central, Oviedo, Idea.

Battisti, C. (1960-61), «Sui grecismi dell’ ittionimia latina», BALM 2,88, 63-81. 
Belon, Pierre (1553), Petri Bellonii Cenomani, De Aquatilibus libri II, cum eiconibus ad vivam ipsorum effigiem, quoad eius fieri potuit, expressis, París, C. Stephanus.

Capponi, F. (1972), P. Ovidii Nasonis Halieuticon, I-II, Leiden, Brill.

CORDE (enero 2021), Real Academia Española: Banco de datos CORDE [en línea]. Corpus diacrónico del español, <http://www.rae.es>.

Cortelazzo, M. (1965), «Primi risultati dell' ALM», BALM 7, 8-31.

DCECH (1991-1997 [1980]), Corominas, J.-Pascual, J.A. Diccionario crítico etimológico castellano e hispánico, Madrid, Gredos.

DCG Du Cange, C du F. (1688), Glossarium ad scriptores mediae et infimae Graecitatis, Lyon, apud Anisonios.

DCL Du Cange, C du F. et al, cum supplem. L Favre (1883-1887 [1678],) Glossarium ad scriptores medice et infimce Latinitatis, Niort, L. Favre, edit. et impr.

De Huerta, Gerónimo (1603), Libro nono de Caio Plinio Segundo, de la Historia Natural de los pescados del mar, de lagos, estanques y ríos, Madrid, por P. Madrigal.

De Pineda, Juan (1589), Los treinta y cinco diálogos de la agricultura cristiana, Salamanca, en casa de P. Adurza y D. López.

De Saint-Denis, E. (1947), Le vocabulaire des animaux marins en latin classique, París, Klincksieck.

Id. (1955), Pline L'Ancien, livre IX, París, Les Belles Lettres.

Id. (1975), Ovide. Halieutiques, París, Les Belles Lettres.

DEL (2001 [1932]), Ernout A.-Meillet A. Dictionnaire étymologique de la Langue Latine. París, Klincksieck, reed. $4^{\mathrm{a}}$ ed., addit. et correc. J. André.

Garcés Gómez, M.P. (1993), «El léxico marinero», AnMal 126, 179-182.

Gessner, Conrad (1558 [1554 ...] ), Conradi Gesneri medici Tigurini Historiae Animalium libri IIII qui est de Piscium et Aquatilium animantium natura, Zúrich, apud Chr. Froschoverum.

Giammarco, E. (1963-64), «Lessico marinaresco abruzzese e molisano», BALM 5-6, 191275.

Gilles, Pierre (1533), Ex Aeliani Historia ..., itemque ex Porphyrio, Heliodoro, Oppiano ... De ui et natura animalium. Eiusdem Gyllii liber unus, De Gallicis et Latinis nominibus piscium, Lyon, apud S. Gryphium.

Giòvio, Paolo (1531[1524]), Pauli Iovii Novocomensis medici De Romanis piscibus libellus, Basilea, in offic. Frobeniana.

González García, E. (2008), Motivación y creación léxica en las hablas populares (léxico de los fenómenos atmosféricos, del mar y del ciclo vital a través del TLHA), Tesis doct., Madrid, Univ. Complutense.

Somolinos, G., Nogués, M.C., Del Pozo, E. (1988), Historia Natural de Cayo Plinio Segundo. Trasladada y anotada por el doctor Francisco Hernández [c.1567...] México, UNAM.

Iglesias Ovejero, A. (2015), «El árbol paremiológico de pedro», AFB.Est.Ling. 5, 79-108.

Landino, Christophoro (1543 [1476]), Historia Naturale di C. Plinio ... di Latino in volgare tradotta, Venecia, Di Ferrari.

Lundström, V. et al. (1897), L. Iuni Moderati Columellae opera quae exstant, Uppsala-Leipzig.

Mata Oroval, X. (2015), Bestiari Llati Polisemàntic: un estudi motivacional, Tesis doct., Valencia, Univ. Valencia.

Mayhoff, C. (1967 [1892-1909]), Plinius, Naturalis Historiae Libri XXXVII, Leipzig, Teubner.

Migliorini, B. (1968 [1927]), Dal nome proprio al nome comune, Florencia, L.S. Olschki. 
Moure Casas, A. (2020) «Arbitrariedad y motivación de ictiónimos: sanmartiño, sanmartín y congéneres», en Conti, L. et al. (edd.), Homenaje Prof. E.Crespo, Madrid, UAM, 617624.

Petschenig, M. (1888) Paulinus Petricordiae, Carmina: Poetae Christiani Minores, CSEL 16/1,Viena, ÖAW.

Rondelet, Guillaume (1554), Gulielmi Rondeletii doctoris medici ... Libri de Piscibus marinis, in quibus uerae piscium effigies expressae sunt, Lyon, apud M. Bonhomme.

Salviani, Ippolito (1554), Aquatilium animalium Historiae liber primus cum eorumdem formis aere excusis, Hippolyto Salviano Typhernate auctore, Roma, apud eundem Salvianum.

Sánchez Prieto, P. (2004), Estéfano de Sevilla, Visita y consejo de médicos. BN de Madrid, ms. 18052, Alcalá Henares, Univ. Alcalá.

Schmidt, M. (1860), Hesychii Alexandrini Lexicon, vol. 2 (E-K), Jena, F. Mauki.

Sillig, I. (1851-1855 [1831-36]), C. Plini Secundi Naturalis Historiae libri XXXVII, Hamburgo y Gotha, A. Perthes.

TLL (1900 ss.), Thesaurus Linguae Latinae, Leipzig-Teubner, Berlín-De Gruyter. 
